\title{
Research on the Application of Intelligence Teaching Mode of Superstar Platform in the Teaching of Experimental Design and Data Processing
}

\author{
Wei Li1, 2, Yudie Li1, 2, Ran Wang1, 2, Wenpin Lv, 2, Yonggang Qi1, 2* \\ ${ }^{1}$ Hubei University of Technology, Wuhan 430068, China \\ ${ }^{2}$ Key Laboratory of Fermentation Engineering (Ministry of Education), Hubei University of Technology, Wuhan 430068, \\ China \\ *Corresponding author: Yonggang Qi, qjg7520@163.com
}

\begin{abstract}
Experimental Design and Data Processing is an important core professional basic course for food science majors. This course is theoretical and practical, and there are many formulas, abstract contents and difficult to understand, and there are some problems in the teaching process, such as students' poor interest in learning, insufficient mastery of what they have learned, and inability to combine theory with practice organically. Through analyzing the existing problems, this paper puts forward some reform measures for the teaching mode of experimental design and data processing by using the intelligent teaching of Superstar platform.
\end{abstract}

Keywords: Experimental design and data processing; Superstar platform; Flip the classroom; Wisdom lesson; Teaching method

Publication date: August 2021; Online publication: August 30, 2021

\section{Introduction}

Experimental Design and Data Processing is a basic course for agronomy majors in agricultural colleges and universities ${ }^{[1]}$. It has the characteristics of many concepts, abstract principles, complex formulas and strong practicality, and is one of the most difficult courses for students to learn. Especially when encountering complex calculation and rigorous reasoning and analysis process, it is difficult for students to understand. Under the background of rapid development of information technology, Superstar Pan-Ya Network Teaching Platform (referred to as Superstar Platform) is used to guide students to master basic concepts, principles, calculation formulas and other contents online. After teachers teach key contents and application cases in class, mainly through teaching methods such as answering questions first, discussing in groups, and turning over classes, students can participate in teaching interaction more, give full play to students' learning enthusiasm, and realize the mixed teaching mode of Experimental Design and Data Processing, in order to obtain better teaching results.

\section{Teaching Scheme Design}

The fundamental starting point of instructional design is to improve the efficiency of learners' acquisition of knowledge and skills and the technical process of interest. Instructional design is an integral part of educational technology, which can use systematic methods to design teaching process and make it a kind 
of the degree of operability ${ }^{[2]}$. When preparing lessons, according to the "Outline" and "Curriculum Standard," the teaching content, teaching objectives and teaching Key points, teaching difficulties, presentations, main teaching methods, teaching tools, time allocation in each stage, teaching process Five links are dealt with: teacher's activities, student's activities, design intention of each stage, after-class evaluation and reflection, etc. In the case, the teaching materials are redeveloped.

Reflection on instructional design: Lin Chongde, a famous psychologist in China, once put forward the growth model of "excellent teacher $=$ teaching process + reflection." Teaching reflection can activate teachers' teaching wisdom, explore new ways of presenting the same in teaching materials, and build a teacher-student interaction mechanism and a new way for students to learn. It is the "catalyst" of our teachers' growth and the important foundation of teachers' development. Generally, from the following four angles:

(1) Reflect on the success and pride

(2) Reflect on mistakes.

(3) Reflect on students' opinions.

(4) Reflect on students' problems and suggestions.

We introduced the online video course Biostatistics and Experimental Design of Huazhong Agricultural University. According to the syllabus, this course is divided into ten chapters according to the teaching objectives, each chapter sets specific learning objectives, and each chapter carries out teaching activities, during and after class. Before class, students use the "Superstar Learning Pass" to guide students to learn by video, so that students can master the basic contents such as concepts, principles and formulas of each chapter; in the class, the combination of traditional classroom and online teaching is adopted. After the teacher explains the key and difficult contents and statistical application cases, the students can truly become the main body of classroom teaching through teaching methods such as group discussion, flipping classroom and in-class test. After class, let students continue to participate in "online" learning and finish homework and discussion on time. Through this mixed teaching mode, the content design promotes the change of the traditional teaching mode based on teachers' teaching, enables students to fully participate in classroom interaction, and gives full play to students' initiative and enthusiasm in learning ${ }^{[3]}$.

\section{Establishment and evaluation of teaching mode}

\subsection{Interactive communication between students and teacher's learning before class}

Online Teachers use the "Superstar Platform" before class, online publishing requires mastering task knowledge points and course videos, setting a video open time period, informing students to complete the course video learning within the time period, and completing the chapter test after watching the video of each chapter ${ }^{[4]}$. Students ask questions online about knowledge points that cannot be understood and digested according to the knowledge points of chapter tasks, and teachers or other students can participate in feedback answers and discussions. Finally, according to the key knowledge points in this chapter and the feedback results of the chapter test, the teacher also publishes relevant discussion topics, guides students to think about problems, and conducts online teacher-student interactive answering questions, which fully realizes the pre-class.

\subsection{Online and offline combination classroom teaching}

Online and offline classroom learning mainly includes students' sign-in, key and difficult analysis, in-class test, application case explanation, group discussion, flipping class, questioning and commenting, etc. Its purpose is to enable more students to actively participate in classroom interaction. The specific classroom 
teaching links are as follows:

(1) Student sign-in: teachers use the "Superstar Platform" to sign in students who participate in classroom learning.

(2) Analysis of key and difficult points: explain the key and difficult contents of the chapter in detail, and the explanation time should not exceed $30 \%$ of the total chapter hours.

(3) In-class test: according to the knowledge points and key contents of the main tasks of the chapter, publish the test questions on the platform, and set a certain time period for students to complete the test online.

(4) Application case explanation: mainly aiming at the key contents such as field experiment design method, hypothesis test and variance analysis, a typical case is designed for each task knowledge point to teach the application process of statistical analysis method in experimental research.

(5) Group discussion and flipping class: according to the key contents in (2) and (4) above, design special topics or cases, and ask students to discuss in groups (3-5 members in each group). After the discussion, use the platform to randomly name and share the results of group discussion by flipping class.

(6) Questions, answers and comments: students ask questions or ask questions according to the discussion results shared by the group representatives, and the group representatives or other group members answer the questions raised by classmates in time. After the students complete the questions and answers, the teacher makes a summary and comments to explain the reasonable and correct answers.

\subsection{Reflection after class}

Reflection after class is an important link in teaching, teachers should summarize the advantages and disadvantages in the teaching process and students' feedback after class, and make profound thinking and analysis, it is beneficial to the improvement of teaching quality in the later period. Compared with traditional classroom teaching, using the "Superstar Learning Link" platform, it is more convenient for teachers to reflect after class. After class, teachers distribute questionnaires on the platform to give online feedback on teaching methods, teaching models and teaching results. At the same time, teachers and students continue to communicate on the platform to solve the remaining doubts. Using the platform expands the scope of communication and improves the quality of reflection after class.

\subsection{Evaluation of students' learning effect}

Relying on platform statistics, record the number of study visits, the number of discussions attended, chapter test times, etc. At the same time, it can record in detail the number of task knowledge points completed by each student, the length of video viewing, and the situation of participating in classroom activities (including sign-in, voting, answering first, scoring, questionnaire, test, etc.). Also, the platform also has the function of inspecting students, after consulting the statistical data of the platform, teachers can supervise the students who are ineffective in online learning and urge them to speed up their learning progress.

Teachers through the platform of performance management, set weights for items such as course videos, chapter quizzes, number of visits, discussions, readings, class interactions, assignments, etc. For example, this semester, the online video of "Field Experiment and Statistical Methods" course was opened to four experimental classes by using the "Superstar Learning Pass" APP, and the course video (40\%), chapter test $(40 \%)$ and participation in discussion $(20 \%)$ were set as one of the usual academic achievements in this 
process assessment. After the students completed their study, the platform gave their achievements according to the set weights.

\section{Thoughts on the application of "Superstar Platform" in mixed teaching}

\subsection{Advantages of practical application of Superstar Platform in mixed teaching mode}

It is convenient to realize the process assessment of teaching courses. The Ministry of Education put forward in the document "Opinions on Accelerating the Construction of High-level Undergraduate Education and Comprehensively Improving Talent Training Ability": to strengthen examination management, strict process assessment, Increase the proportion of process assessment scores in the total scores of courses. If teachers still use traditional teaching classrooms, it is difficult to achieve process assessment. For example, the theoretical class hours of Experimental Design and Data Processing in our school are 50 hours, the syllabus requires teaching the contents of 10 units, there are many concepts involved, abstract principles and complex formulas. It is difficult for most students in class to understand and digest all the knowledge points. If the process assessment is carried out in the traditional classroom, It is necessary to explain clearly the concepts, principles and application cases of each knowledge point, students should also participate in classroom interaction (answering questions first, discussing in groups, turning over classes, etc.), 100 class hours are estimated to be difficult to complete. However, using the advanced technology and platform of modern informatization, a lot of tedious work such as concept statement, principal explanation and formula deduction are taught by online video. Not only can students repeat their studies many times, better understanding of abstract and complex content, and students can have more time to participate in teaching links such as asking questions, answering questions first, discussing and displaying results online and offline, which is convenient for teachers to conduct comprehensive process evaluation of students in each link ${ }^{[5]}$.

It is helpful to improve students' comprehensive ability. Using the "Superstar Platform," let students fully participate in the whole process of teaching before, during and after class, this "student-centered" mixed teaching mode is more likely to stimulate students' internal motivation of active exploration, independent thinking and good at discovering laws. The mixed teaching classroom is based on the traditional classroom learning mode of "listening and speaking." Incorporate multiple learning methods such as "answering questions first," "group discussion" and "turning over the classroom," it is helpful to improve students' learning effect, promote students' autonomous learning and thinking ability, and promote healthy and all-round development. More importantly, students' comprehensive abilities such as autonomous learning ability, language expression ability and teamwork consciousness have been greatly improved through the active interaction of "active participation" in class.

\subsection{There are still problems in the application of mixed teaching mode}

Although the mixed teaching mode based on modern information technology has brought about a change in current education and teaching, but there are still some problems in the teaching mode. First of all, teachers carefully construct online curriculum resources, whether it can arouse students' interest in learning, let students devote themselves to learning. For teachers who have just stepped down from the traditional classroom, it is difficult to achieve in the short term. Secondly, the way students are used to learning is difficult to change in the short term. Although students are familiar with the Internet and smart phones, online and offline mixed teaching is also a brand-new learning mode for most students. It is difficult for some students to change into the learning concept of "I want to learn" in a short time ${ }^{[6]}$. Therefore, the promotion of the mixed teaching mode based on information technology has been further strengthened, through project guidance, introduction demonstration, conference training and other ways, teachers and students should change their thoughts and actions, so that students can establish the concept of independent 
learning and innovation as soon as possible, improve their self-study ability in an all-round way, stimulate their innovative consciousness, cultivate their innovative spirit and creative thinking, and lay a foundation for future creative work.

\section{Conclusion}

There are some problems in the teaching process, such as students' poor interest in learning, insufficient mastery of what they have learned, and inability to combine theory with practice organically. Through analyzing the existing problems, this paper puts forward some reform measures for the teaching mode of experimental design and data processing by using the intelligent teaching of Superstar platform.

\section{Funding}

The foundation for Teaching Research Project of Hubei University of Technology in Hubei Province in 2020(grant number 2020017).

\section{Disclosure statement}

The authors declare that there is no conflict of interest.

\section{References}

[1] Moretti K, Aluisio A, Chen J, et al., 2020, 43 Knowledge and Confidence in the Treatment of Emergent Conditions among Graduating Medical Students Across Colombia. Annals of Emergency Medicine, $76(4 \mathrm{~S})$.

[2] Bazan D, Nowicki M, Rzymski P, 2021, Medical Students as the Volunteer Workforce during the COVID-19 Pandemic: Polish Experience. International Journal of Disaster Risk Reduction, 55.

[3] Likhitsathian S, et al., 2021, Cross National Comparison of Medical Students' Attitudes and Beliefs about Medical Cannabis and its Application for Pain Management. Complementary Therapies in Medicine, 59 (prepublish).

[4] Fulton K, 2012, Upside Down and Inside Out: Flip Your Classroom to Improve Student Learning. Learning \& Leading with Technology. 39(8): 12-7.

[5] Mattis K, 2015, Flipped Classroom Versus Traditional Textbook Instruction: Assessing Accuracy and Mental Effort Different Levels of Mathematical Complexity. Technology Knowledge and Learning. 20(2): 231-48.

[6] Dederichs M, Weber J, et al., 2021, Exploring Medical Students' Views On Digital Mental Health Interventions: A Qualitative Study. Internet Interventions, 2021 (prepublish). 